\title{
Design Tools for Bolted End-Plate Beam-to-Column Joints
}

\author{
Giusy Terracciano (D), Gaetano Della Corte, Gianmaria Di Lorenzo, and Raffaele Landolfo
}

University of Naples Federico II, Department of Structures for Engineering and Architecture, Italy

Correspondence should be addressed to Giusy Terracciano; giusy.terracciano@unina.it

Received 1 December 2017; Accepted 14 May 2018; Published 5 July 2018

Academic Editor: Yaowen Yang

Copyright (C) 2018 Giusy Terracciano et al. This is an open access article distributed under the Creative Commons Attribution License, which permits unrestricted use, distribution, and reproduction in any medium, provided the original work is properly cited.

\begin{abstract}
Predicting the response of beam-to-column joints is essential to evaluate the response of moment frames. The well-known component method is based on a mechanical modelling of the joint, through joint subdivision into more elementary components subsequently reassembled together to obtain the whole joint characteristics. Significant advantages of the component method are the following: (i) the mechanics-based modelling approach; (ii) the easier general characteristics of components. However, the method is commonly perceived by practicing engineers as being too laborious for practical applications. Within this context, this paper summarizes the results of a theoretical study aiming to develop simplified analysis tools for bolted end-plate beamto-column joints, based on the Eurocode 3 component method. The accuracy of the component method was first evaluated, by comparing theoretical predictions of the plastic resistance and initial stiffness with corresponding experimental data collected from the available literature. Subsequently, design/analysis charts were developed through a parametric application of the component method by means of automatic calculation tools. They are easy and quick tools to be used in the first phases of the design process, in order to identify joint configurations and geometrical properties satisfying specified joint structural performances. The parametric analysis allowed also identifying further simplified analytical tools, in the form of nondimensional equations for predicting quickly the joint structural properties. With reference to selected geometries, the approximate equations were verified to provide sufficiently accurate predictions of both the stiffness and the resistance of the examined beam-to-column joints.
\end{abstract}

\section{Introduction}

Beam-to-column joints are essential components significantly affecting the overall structural response [1]. Methods are currently available for calculating stiffness and plastic resistance of beam-to-column joints. The well-known "component method" is perhaps the most comprehensive and general analysis method [2-4]. The component method, currently endorsed by Eurocode 3 (EC3) [5], offers the potential for applications to many different situations, provided that individual joint components are properly characterized and assembled. Besides, the method could be considered as a compromise between precision (complexity) and usability (speed of implementation). Notwithstanding, the method is commonly perceived by practicing engineers as being too laborious for practical applications, especially during first design phases where a rough but quick estimation of joint properties would be appropriate. In this context, the paper describes studies carried out to investigate potentials for developing easy-to-use analysis/design tools, in order to predict the response of bolted end-plate joints quickly during the first phases of the design process. Mechanical characterization of bolted beam-to-column joints, as well as development of simplified structural behaviour prediction tools, continues to be topics of great interest, as demonstrated by recent research activities in this field [6]. In the following, the theoretical predictions provided by the component method of EC3 were first compared with some experimental data collected from the available technical literature. Subsequently, design/analysis charts were developed through a parametric application of the component method. Eventually, preliminary approximate equations were proposed for bolted extended end-plate joints.

\section{Accuracy of the Eurocode 3 Component Method for Bolted End-Plate Joints}

2.1. Experimental Data Collection and Comparison Criteria. Several experimental tests have been performed during the 


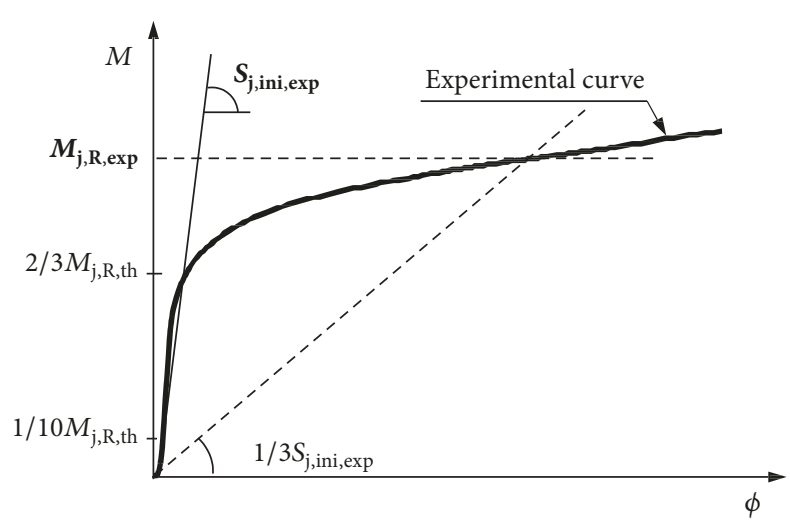

FIGURE 1: Experimental value of initial stiffness and plastic resistance.

last decades to investigate the behaviour of bolted endplate beam-to-column joints. A collection of 62 specimens was obtained from the available literature and essential data pertaining to the tests were organized and managed using a purposely developed digital database. The theoretical initial rotational stiffness and moment resistance of the tested specimens were then calculated using the component method implemented into EC3. Subsequently the theoretical predictions were compared to the corresponding experimental results. In this regard, it is worth pointing out that the theoretical moment resistance of joints was calculated assuming actual values of material properties and unit values for partial factors. The experimental value of initial stiffness was evaluated as the slope of a line passing through two points of the experimental response curve, points identified by the moments equal to $1 / 10$ and $2 / 3$ of the joint plastic resistance $\left(M_{\mathrm{j}, \mathrm{R}, \mathrm{th}}\right)$. Such procedure is illustrated in Figure 1. As far as joint plastic resistance is concerned, it was assumed equal to beam plastic resistance, for full strength joints. Instead, the experimental plastic resistance of partial strength joints was evaluated as the flexural resistance corresponding to a secant stiffness equal to $1 / 3$ of the initial rotational stiffness (Figure 1), coherently with the modelling approach of EC3. The following Sections 2.2 and 2.3 summarize the theoretical versus experimental results comparison for extended and flush end-plate joints, respectively.

2.2. Extended End-Plate Joints. With reference to beamto-column joints with extended end-plate connections, the experimental results presented in [8-16] were considered. Figure 2(a) shows the ratios of the theoretical moment resistance $\left(M_{\mathrm{j}, \mathrm{R}, \mathrm{th}}\right)$ and the experimental moment resistance $\left(M_{\mathrm{j}, \mathrm{R}, \exp }\right)$.

Figure 2(b) illustrates the ratios of the theoretical initial stiffness $\left(S_{\mathrm{j}, \text { ini,th }}\right)$ and the experimental initial stiffness $\left(S_{j, \text { ini,exp }}\right)$. Results in Figure 2 indicate that the EC3 method provides a sufficiently reliable estimation of joint plastic resistance. Instead, the initial stiffness tends to be overestimated. The average ratio of theoretical and experimental values of moment resistances was 0.87 , while the standard deviation of the same ratio was 0.18 (Figure $2(\mathrm{a})$ ). The ratio between the theoretical and the experimental initial stiffness has a mean value equal to 1.50 and a standard deviation of 0.90 (Figure 2(b)).

2.3. Flush End-Plate Joints. With reference to beam-tocolumn joints with flush end-plate connections, the experimental results provided in [13, 17-19] were considered. Comparison of the theoretical predictions and the experimental results confirms observations already done for extended end-plate connections. The component method provides a theoretical moment resistance reasonably close to the experimental value, but the method tends to overestimate the initial stiffness. As shown in Figure 3, the ratio of the theoretical and the experimental values of the plastic resistance has a mean value of 1.07 and a standard deviation value equal to 0.17 (Figure 3(a)). The ratio of the theoretical to experimental initial stiffness has mean and standard deviation values equal to 2.62 and 1.12, respectively (Figure 3(b)).

\section{Easy-to-Use Design Charts}

3.1. Basic Assumptions. The EC3 component method was extensively applied in order to explore the moment-rotation response of beam-to-column bolted end-plate joints by varying a number of geometrical properties. One result of this parametric application was the development of charts which could be useful tools to design the joints, quickly but with the same level of reliability as done by a specific application of the EC3 method on a case-by-case basis.

For design purposes and according to a common design practice, column and beam cross sections as well as material properties were assumed to be preliminarily known. Endplate thickness and bolt diameter were considered as main design variables. Instead, assumptions were made on the other geometrical parameters (Figure 4) involved. For flush end-plate joints (Figure 4(a)), the internal lever $\operatorname{arm}(z)$ was assumed to be equal to $80 \%$ of the beam height. The horizontal bolt spacing $(w)$ was assumed to be equal to the average value between the minimum and the maximum spacing $(p)$ that are allowed for a given column shape. For extended end-plate joints (Figure 4(b)), the vertical bolt spacing was fixed equal to the horizontal one $(w)$; i.e., square bolt arrangements were considered. For extended end-plate joints, configurations with or without continuity plates, as well as with or without end-plate stiffeners, were considered. Continuity plates were assumed to have a thickness equal to the beam flange thickness. The thickness of the endplate vertical stiffener was assumed equal to the beam web thickness. For both flush and extended end-plate joints, the effect of a column web panel diagonal stiffener (i.e., the role of the column web panel flexibility in shear) was also investigated. In the analysis, distances of bolts from all plate edges satisfied the requirements stipulated by EC3.

3.2. Results. Graphs were developed to provide normalized stiffness $\left(k_{\mathrm{b}}\right)$, normalized resistance $\left(m_{\mathrm{b}}\right)$ and plastic mechanism of beam-to-column joints with variable endplate thickness and bolt diameter. Definitions of $k_{\mathrm{b}}$ and $m_{\mathrm{b}}$ are according to EC3 [5]. $k_{\mathrm{b}}$ is the ratio between the 

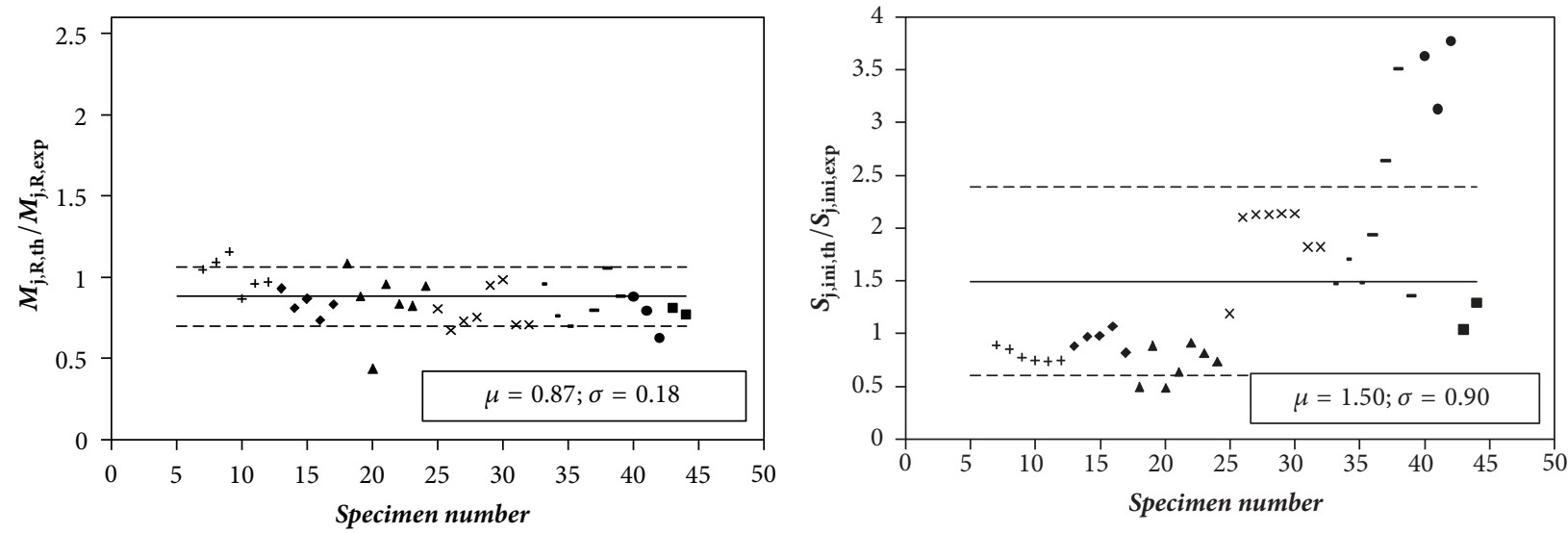

$\times$ Coelho et al 2004

+ Nogueiro et al 2006

- Shi et al 2007 [12]

- Shi et al 2007 [13]

- Coelho \& Bijlaard 2007

- Tahir \& Hussein 2008

- Iannone et al 2011

- Abidelah et al 2012

(a)
$\times$ Coelho et al 2004
+ Nogueiro et al 2006
- Shi et al 2007 [12]
• Shi et al 2007 [13]
- Coelho \& Bijlaard 2007
- Tahir \& Hussein 2008
- Iannone et al 2011
- Abidelah et al 2012

Figure 2: Ratios of theoretical to experimental moment resistance (a) and initial stiffness (b) for extended end-plate joints [7].

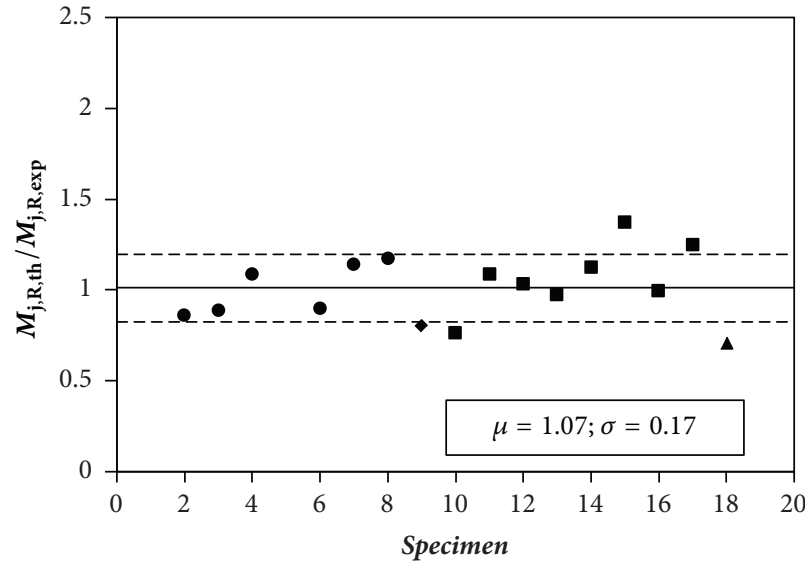

- Broderick \& Thomson 2002

- da Silva et al 2004

- Broderick \& Thomson 2005

^ Shi et al 2007 [13]

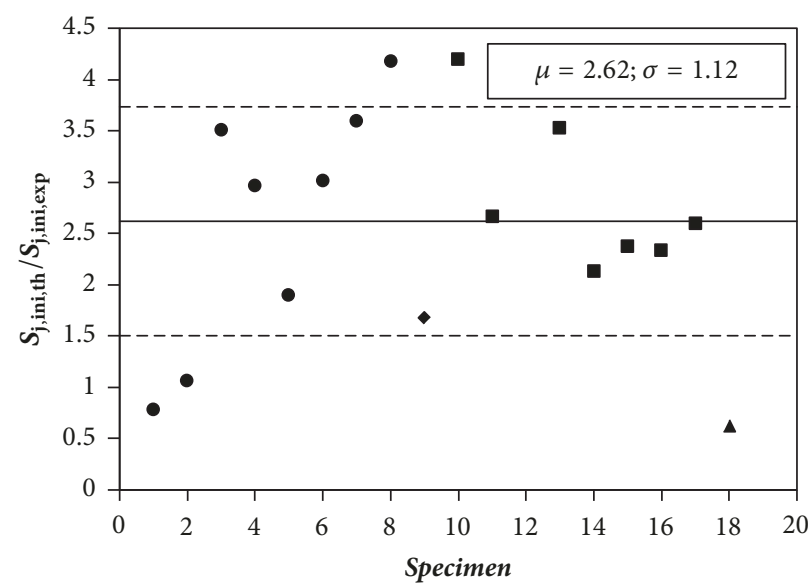

- Broderick \& Thomson 2002

- da Silva et al 2004

- Broderick \& Thomson 2005

^ Shi et al 2007 [13]

(a)

(b)

Figure 3: Ratios of theoretical to experimental moment resistance (a) and initial stiffness (b) for flush end-plate joints [7].

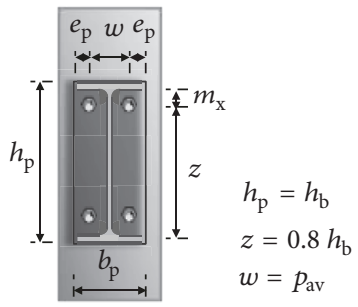

(a)

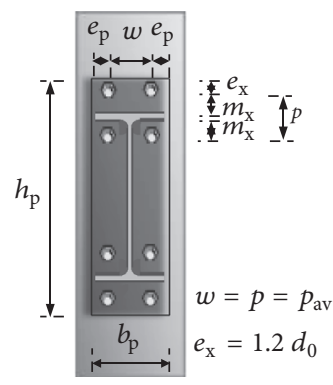

(b)

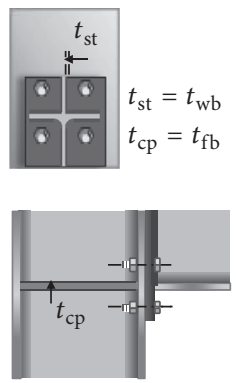

FIgURE 4: Basic assumptions and arrangements for flush (a) and extended (b) end-plate joints [7]. 


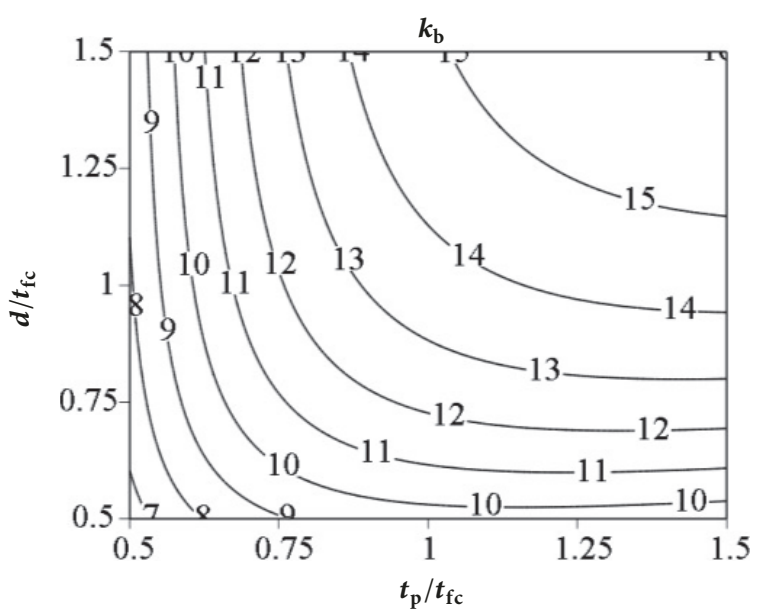

(a)

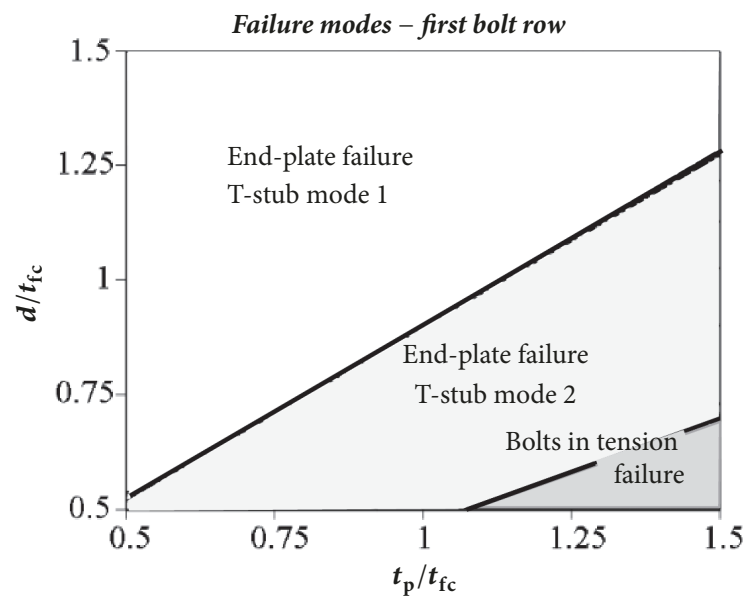

(c)

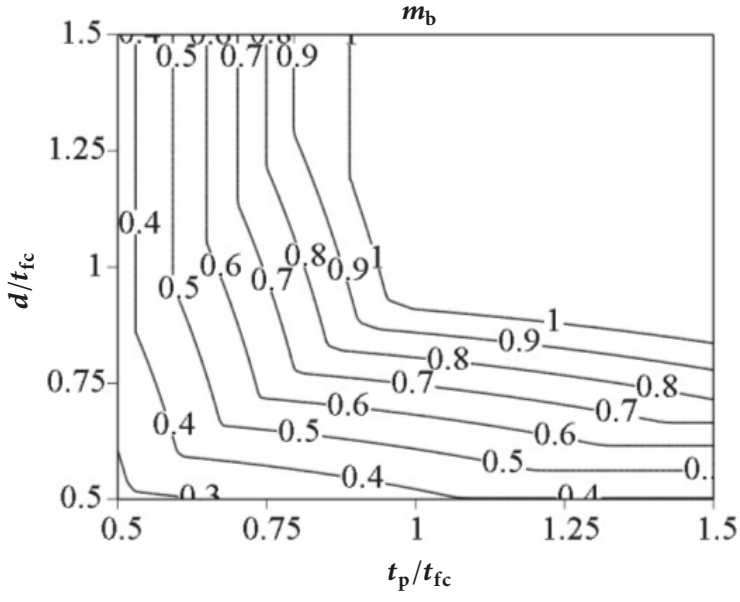

(b)

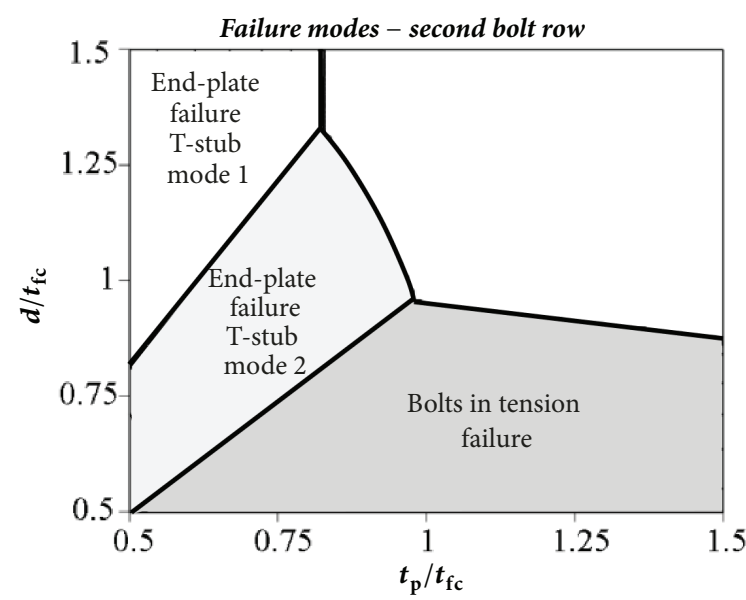

(d)

FIGURE 5: Normalized stiffness (a), normalized resistance (b), and failure modes for the first (c) and the second bolt row (d) of extended end-plate connections (column shape: HEM 280; beam shape: IPE 500; steel grade S275; bolt grade 8.8) [7].

joint rotational stiffness $\left(S_{\text {,ini,th }}\right)$ and the flexural stiffness of the connected beam $\left(E I_{\mathrm{b}} / L_{\mathrm{b}}\right) ; m_{\mathrm{b}}$ is the ratio between the resistance moment of the joint $\left(M_{\mathrm{jR}}\right)$ and the beam plastic moment $\left(M_{\mathrm{bpl}, \mathrm{R}}\right)$. Samples of the graphs are shown in Figure 5, with reference to a beam-to-column joint having the following characteristics:

(i) Column shape: HEM 280

(ii) Beam shape: IPE 500

(iii) Continuity plate: yes

(iv) Steel grade: S275

(v) Bolt grade: 8.8 .

In each graph of Figure 5, the $\mathrm{x}$-axis plots the ratio of the end-plate thickness $\left(t_{\mathrm{p}}\right)$ and the column flange thickness $\left(t_{\mathrm{fc}}\right)$, while the y-axis plots the ratio of the bolt diameter $(d)$ and the column flange thickness. Both the ratios $t_{\mathrm{p}} / t_{\mathrm{fc}}$ and $d / t_{\mathrm{fc}}$ were assumed to vary from 0.5 to 1.5 .
Figure 5 shows contour lines corresponding to different values of normalized stiffness $\left(k_{\mathrm{b}}\right.$, Figure $\left.5(\mathrm{a})\right)$ and normalized resistance $\left(m_{\mathrm{b}}\right.$, Figure 5(b)). For any selected endplate thickness and bolt diameter, the graphs simply and quickly allow classifying the joint as per the Eurocode 3 rules. Failure modes associated with each combination of design parameters can also be identified. Figure 5(c) illustrates the variation of the failure mode for the first bolt row, while Figure 5(d) is similar, but relevant to the second bolt row. In general, the bolt rows of extended end-plate joints are characterized by different failure modes. However, for certain ranges of the design parameters, the failure mode of the two bolt rows can be equal (Figures 5(c) and 5(d)). On one hand, the results shown in Figure 5 allow a clear identification of the structural behaviour of an end-plate joint, with variable geometrical design parameters. On the other hand, for any required joint performance in terms of normalized rotational stiffness, normalized moment resistance, and/or yielding mechanism, the graphs permit the selection of the 


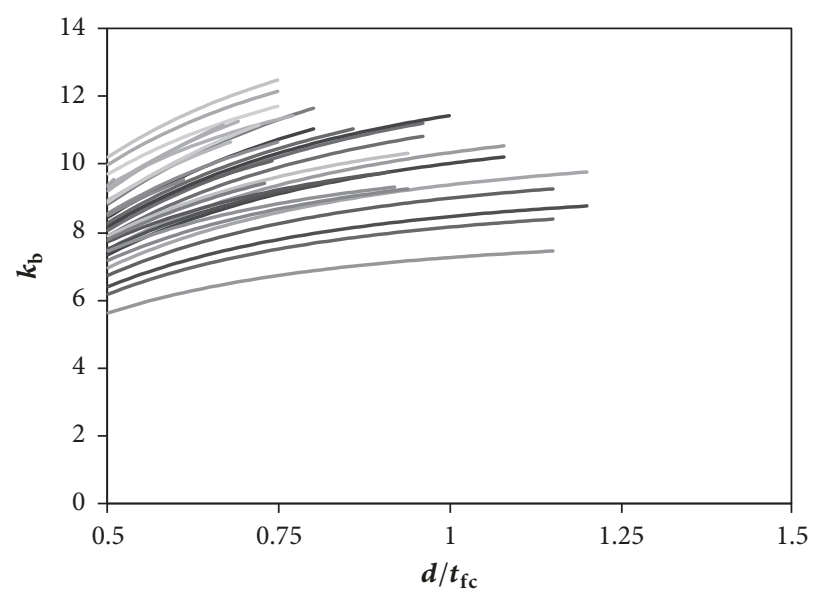

(a)

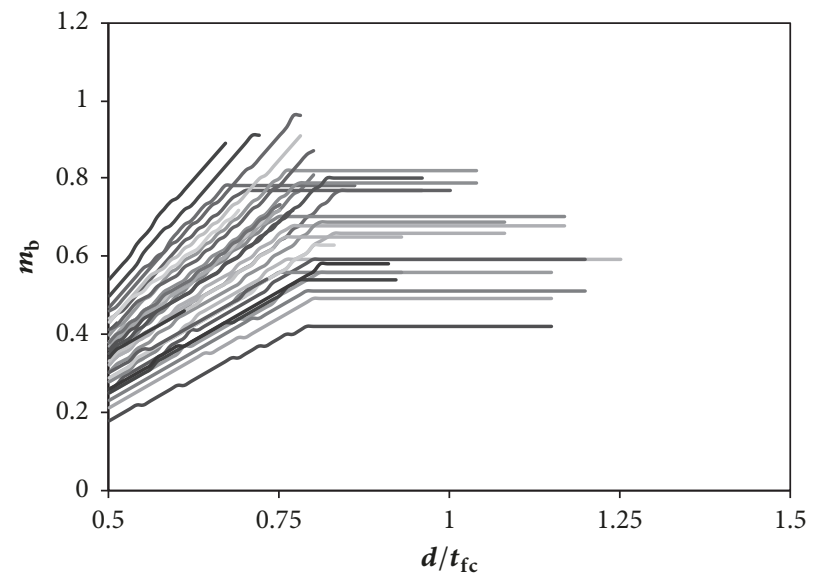

(b)

FIGURE 6: $k_{\mathrm{b}}$ versus $d / t_{\mathrm{fc}}(\mathrm{a})$ and $m_{\mathrm{b}}$ versus $d / t_{\mathrm{fc}}$ (b) curves for beam-to-column assemblages combining I section beams (varying from IPE 200 to IPE 750) and wide flange section columns (varying from HEM 120 to HEM 400) obtained using design charts.

geometrical parameters satisfying the requirements. More details about this theoretical study can be found in $[7,20]$.

\section{Approximate Equations}

4.1. Overview and Hypothesis of the Study. The parametric study described in the previous section allowed for evaluating relationships such as $k_{\mathrm{b}}$ versus $d / t_{\mathrm{fc}}$ and $m_{\mathrm{b}}$ versus $d / t_{\mathrm{fc}}$, given the ratio $t_{\mathrm{p}} / t_{\mathrm{fc}}$. The comparison of such curves corresponding to several different beam-to-column joints allowed for developing closed-form approximate equations for the initial stiffness and resistance of extended end-plate joints.

The study was carried out considering beam-to-column assemblages combining European I section beams (varying from IPE 200 to IPE 750) and wide flange section columns (varying from HEM 120 to HEM 400). The end-plate thickness was assumed equal to the column flange thickness (i.e., $\left.t_{\mathrm{p}} / t_{\mathrm{fc}}=1\right)$. Continuity plates were included.

4.2. Normalized Stiffness and Resistance for Extended EndPlate Joints. Figure 6 plots $k_{\mathrm{b}}$ versus $d / t_{\mathrm{fc}}$ and $m_{\mathrm{b}}$ versus $d / t_{\mathrm{fc}}$ curves calculated for all possible beam-to-column joints assembled as described previously. Such curves do not cover the entire range of the independent variable $d / t_{\mathrm{fc}}$, because they reflect the actual bolt diameter that can be used in the connection. In fact, given the column section and the horizontal bolt spacing (Section 3.1), the considered bolt diameters are only those satisfying the EC3 requirements for distances of the bolt axis from plate edges.

Interestingly, $k_{\mathrm{b}}$ versus $d / t_{\mathrm{fc}}$ (Figure 6(a)) and $m_{\mathrm{b}}$ versus $d / t_{\mathrm{fc}}$ (Figure 6(b)) curves do not change shape as the beamto-column combination. Instead, depending on the specific beam-to-column arrangement, such curves are shifted relative one each other along $\mathrm{y}$-axis. In particular, given a beam-to-column arrangement, a beam section size increase produces a downward shift of the curve, while the column section size increase causes a shift upwards of the same curve. This result suggests the use of a single generalized curve (in the form of a master curve) to predict the normalized stiffness and resistance at different beam-to-column combinations. This mathematical representation has the great advantage of enclosing in a single function the effect of all the involved variables: $d / t_{\mathrm{fc}}$ and the beam-to-column configuration. Such a model requires, first the identification of relationship between the parameter at the independent variable $d / t_{\mathrm{fc}}$ and, subsequently, the definition of shift factors allowing for the characterization of such function at different beam-tocolumn joints.

As far as the normalized stiffness is concerned (Figure $6(\mathrm{a}))$, it was observed that $k_{\mathrm{b}}$ versus $d / t_{\mathrm{fc}}$ relationship can be captured by a $3^{\text {rd }}$ degree polynomial function. In order to define such an equation for the stiffness master curve, each $k_{\mathrm{b}}$ versus $d / t_{\mathrm{fc}}$ curve of Figure 6(a), assumed as defined over the entire range of the variable, was shifted by the ratio $k_{\mathrm{b}, 1.5} / 25$, where $k_{\mathrm{b}, 1.5}$ is the ordinate of a curve corresponding to the abscissa $d / t_{\mathrm{fc}}$ equal to 1.5. The graphs of the functions $25 k_{\mathrm{b}} / k_{\mathrm{b}, 1.5}$ versus the parameter $d / t_{\mathrm{fc}}$ are illustrated in Figure $7(\mathrm{a})$ as thin solid lines. As shown, they are almost perfectly superposed with each other and to the average curve, selected as representative of the of the entire class of joints. Regression analysis using the least squares method allowed for the calculation of the equation of the average curve. As a result, the normalized stiffness of extended end-plate joints can be approximately evaluated by means of a generalized cubic function, such as:

$$
\begin{aligned}
k_{\mathrm{b}} & =\left[8.343\left(\frac{d}{t_{\mathrm{fc}}}\right)^{3}-33.3\left(\frac{d}{t_{\mathrm{fc}}}\right)^{2}+47.32\left(\frac{d}{t_{\mathrm{fc}}}\right)\right. \\
& +0.865] \frac{k_{\mathrm{b}, 1.5}}{25}
\end{aligned}
$$

The graph of (1) is shown in Figure $7(a)$ as a bold line. In the previous equation $k_{\mathrm{b}, 1.5}$ is the shift factor allowing for identification of curves corresponding to a specific beam-tocolumn joints. Simplified equation for the calculation of such 


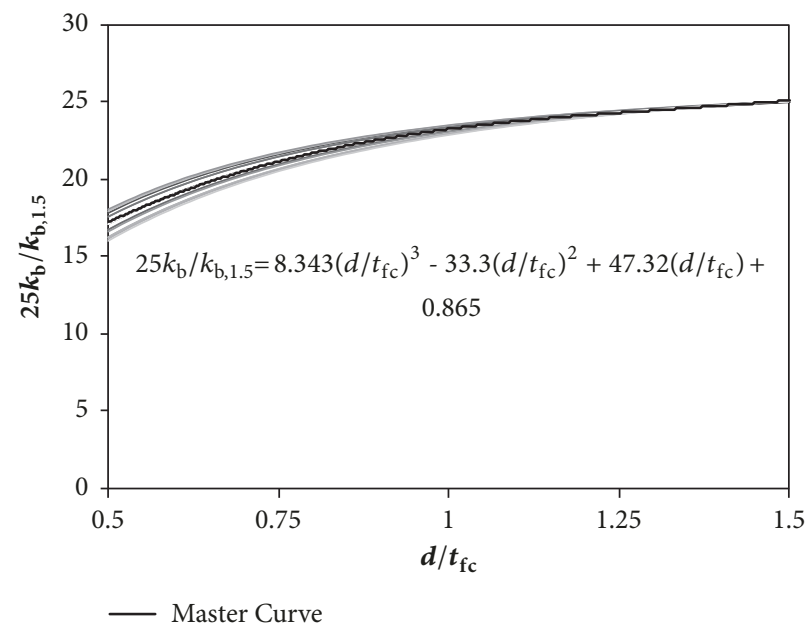

(a)

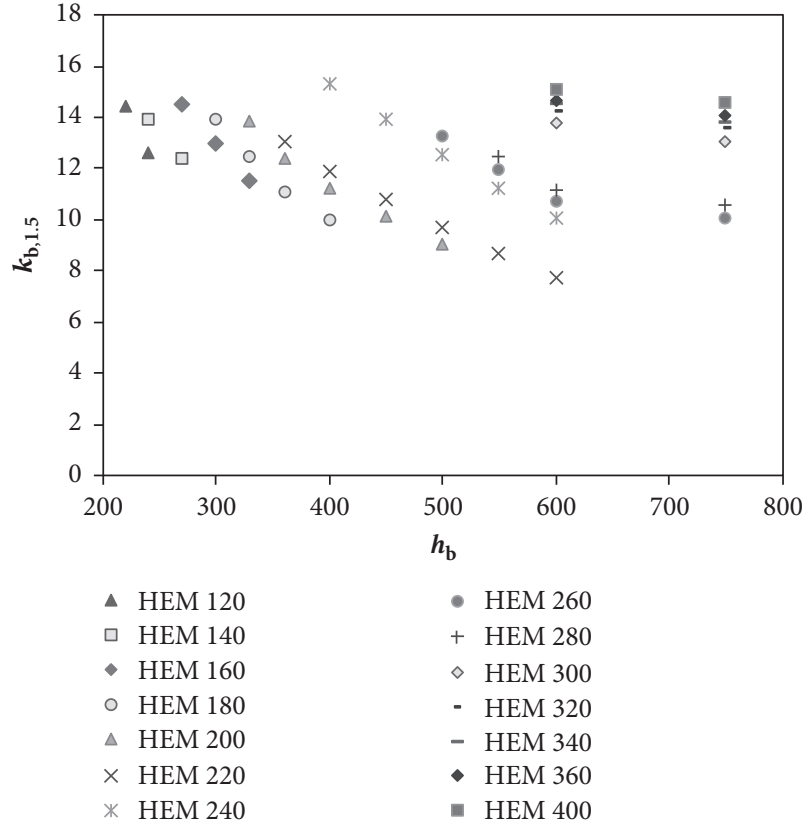

(b)

FIGURE 7: $25 k_{\mathrm{b}} / k_{\mathrm{b}, 1.5}$ versus $d / t_{\mathrm{fc}}$ relationship (a) and the curve shifting factor $k_{\mathrm{b}, 1.5}(\mathrm{~b})$.

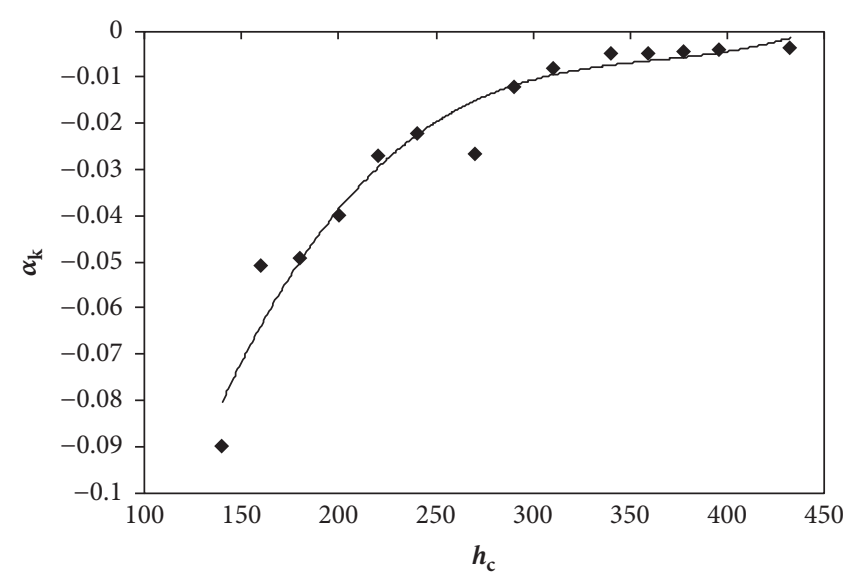

(a)

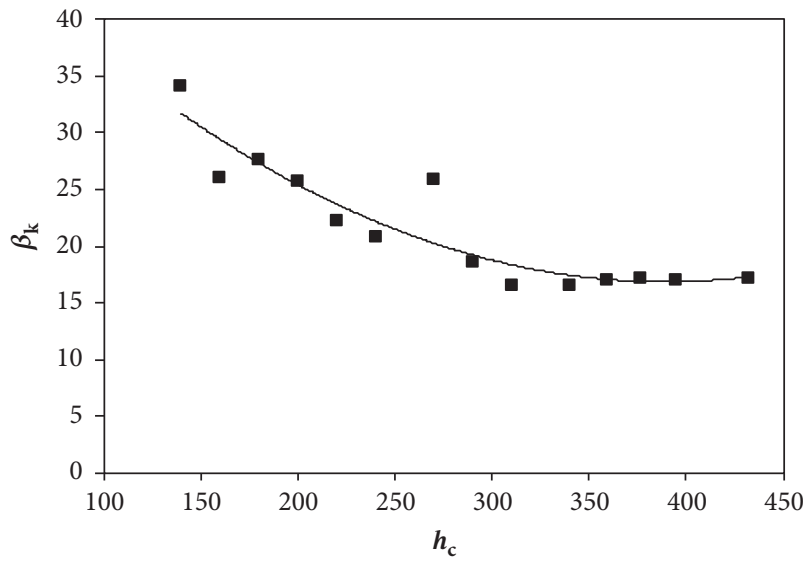

(b)

FIGURE 8: $\alpha_{\mathrm{k}}$, (a) and the intercept $\beta_{\mathrm{k}}$ (b) of equation (2).

beam-to-column dependent coefficient was also investigated. At this aim, $k_{\mathrm{b}, 1.5}$ values were plotted as a function of the beam height $\left(h_{\mathrm{b}}\right)$ in Figure $7(\mathrm{~b})$. Different symbols for data joints highlight trends associated with different column shapes. From Figure 7(b) a linear correlation between $k_{\mathrm{b}, 1.5}$ and $h_{\mathrm{b}}$ can be found for a given column section. Consequently, $k_{\mathrm{b}, 1.5}$ was assumed as a linear function of the beam height $\left(h_{\mathrm{b}}\right)$, evaluable through the following:

$$
k_{\mathrm{b}, 1.5}=\alpha_{\mathrm{k}} h_{\mathrm{b}}+\beta_{\mathrm{k}}
$$

In (2) the angular coefficient, $\alpha_{k}$, and the intercept of the linear function, $\beta_{\mathrm{k}}$, are not constant quantities but they appeared to vary with the column shape (Figure $7(\mathrm{~b})$ ). Figure 8(a) shows the identified correlation between $\alpha_{\mathrm{k}}$ and the column shape, while Figure 8(b) illustrates the relationship between $\beta_{\mathrm{k}}$ and the same variable $h_{\mathrm{c}}$. Each point of such graphs represents the value of the slope or the intercept of the linear correlation found in Figure 7(b), at a particular column section height $\left(h_{\mathrm{c}}\right)$. Correlation analyses resulted in the following:

$$
\begin{aligned}
& \alpha_{\mathrm{k}}=-1.35 \cdot 10^{-6} h_{\mathrm{c}}^{2}+1 \cdot 10^{-3} h_{\mathrm{c}}-0.188 \\
& \beta_{\mathrm{k}}=2.39 \cdot 10^{-4} h_{\mathrm{c}}^{2}-0.19 h_{\mathrm{c}}+53.12
\end{aligned}
$$

With reference to the normalized resistance, Figure 6(b) shows that each $m_{\mathrm{b}}$ versus $d / t_{\mathrm{fc}}$ curve could be fitted by a bilinear function. Regression analysis using the least squares method resulted into two different generalized equations, 


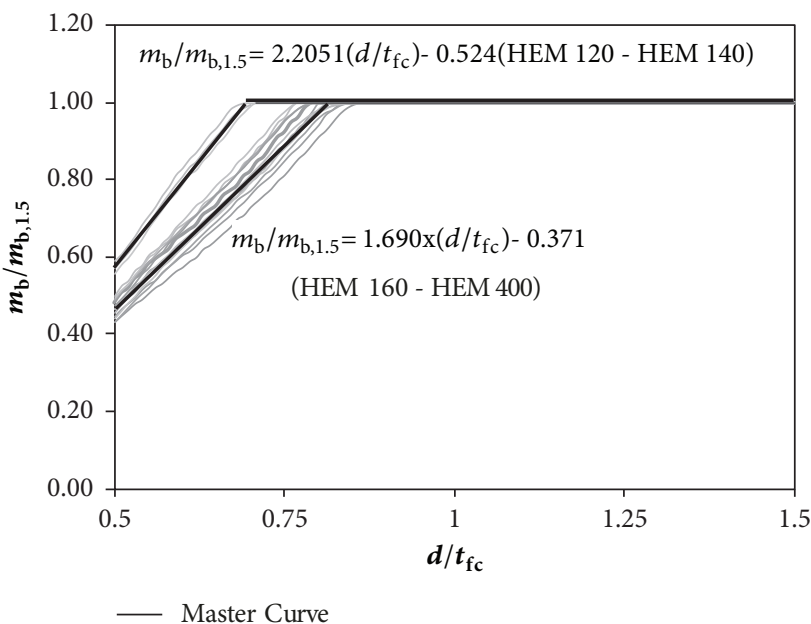

(a)

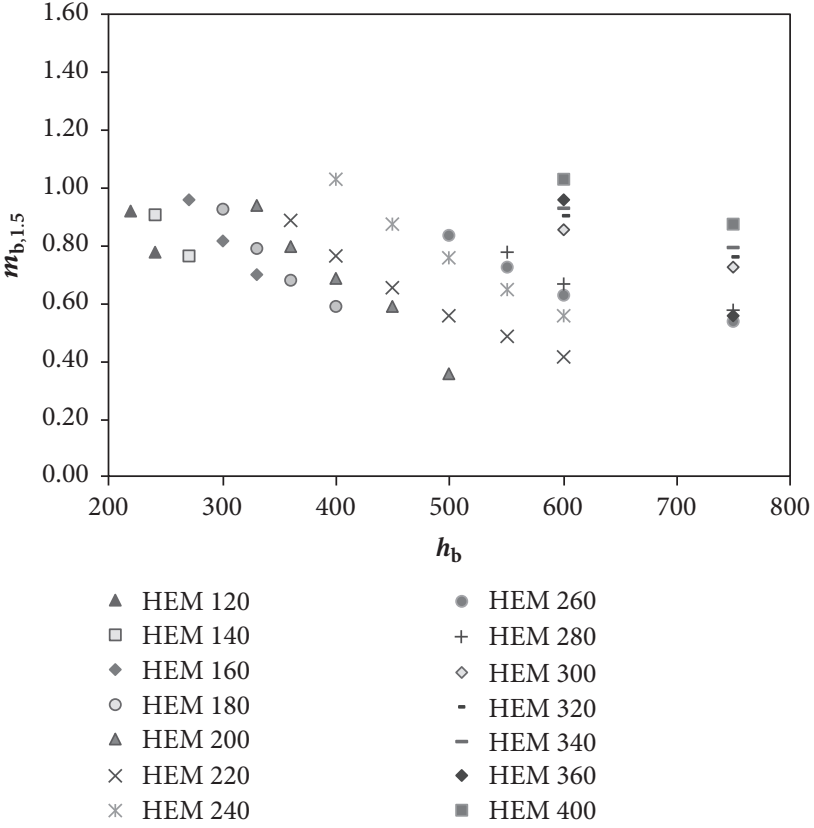

(b)

FIGURE 9: $m_{\mathrm{b}} / m_{\mathrm{b}, 1.5}$ versus $d / t_{\mathrm{fc}}$ relationship (a) and the shifting factor $m_{\mathrm{b}, 1.5}$ (b).

depending on the column section size. Equation (5) can be used to estimate $m_{\mathrm{b}}$ in case of beam-to-column joints having HEM 120 or HEM 140 column cross section. Equation (6) provides the normalized resistance for column cross sections varying from HEM 160 to HEM 400. The graphs of the proposed bilinear functions are depicted in bold in Figure 9(a). They are the average curve for the two set of curves plotted in the same figure, representing $m_{\mathrm{b}}$ versus $d / t_{\mathrm{fc}}$ curves of Figure 6(b), assumed, as for stiffness, to be defined over the entire range of the variable and shifted by $m_{\mathrm{b}, 1.5}$, that is, the ordinate corresponding to the abscissa $d / t_{\mathrm{fc}}$ equal to 1.5 .

$$
\begin{gathered}
m_{\mathrm{b}}=\left[2.205\left(\frac{d}{t_{\mathrm{fc}}}\right)-0.524\right] m_{\mathrm{b}, 1.5} \\
\text { but } m_{\mathrm{b}} \leq m_{\mathrm{b}, 1.5}(\text { HEM } 120-\text { HEM 140) } \\
m_{\mathrm{b}}=\left[1.690\left(\frac{d}{t_{\mathrm{fc}}}\right)-0.371\right] m_{\mathrm{b}, 1.5} \\
\text { but } m_{\mathrm{b}} \leq m_{\mathrm{b}, 1.5}(\text { HEM } 160-\text { HEM 400) }
\end{gathered}
$$

In (5) and (6) $m_{\mathrm{b}, 1.5}$, as for normalized stiffness, represents the shift factor allowing for the characterization of curves corresponding to a specific beam-to-column joints. Similar to what is shown in Figure 7(b), to highlight possible tendencies with both the beam and the column shape, $m_{\mathrm{b}, 1.5}$ values were plotted as a function of the beam cross section height (Figure 9(b)). Also in this case, a linear correlation was identified between the shifting factor and the beam cross section height, as follows:

$$
m_{\mathrm{b}, 1.5}=\alpha_{\mathrm{m}} h_{\mathrm{b}}+\beta_{\mathrm{m}}
$$

As for the stiffness, the angular coefficient, $\alpha_{\mathrm{m}}$, and the intercept of the linear function, $\beta_{\mathrm{m}}$, appeared to vary with the column section (Figures 10(a) and 10(b)).

As illustrated in Figure 10(a), two relationships were derived between $\alpha_{\mathrm{m}}$ and $h_{\mathrm{c}}$. A quadratic correlation function (see (8)) was identified between the angular coefficient and the column cross-sectional height, in case of a column shape varying from HEM 120 to HEM 280; instead, a constant value (see (9)) can be assumed for beam-to-column joints having column cross section varying from HEM 300 to HEM 400. Concerning the intercept, Figure 10(b) revealed a linear relationship between $\beta_{\mathrm{m}}$ and $h_{\mathrm{c}}$, even though also in this case two different linear laws were identified. Equations (10) and (11) are proposed, depending on the column shape, as established for $\alpha_{\mathrm{m}}$.

$$
\alpha_{\mathrm{m}}=-1.404 \cdot 10^{-7} h_{\mathrm{c}}^{2}+9.466 \cdot 10^{-5} h_{\mathrm{c}}-0.0169
$$

(HEM 120 - HEM 280)

$$
\begin{aligned}
& \alpha_{\mathrm{m}}=9.282 \cdot 10^{-4} \quad(\text { HEM } 300-\text { HEM 400) } \\
& \beta_{\mathrm{m}}=-5.799 \cdot 10^{-3} h_{\mathrm{c}}+3.142
\end{aligned}
$$

(HEM 120 - HEM 280)

$$
\beta_{\mathrm{m}}=0.003 h_{\mathrm{c}}+0.344 \quad(\text { HEM } 300-\text { HEM 400) }
$$

4.3. Accuracy of Proposed Approximate Equations. In this first phase of the study, accuracy of the approximate equations was evaluated by comparing their predictions with the results from the EC3 component method. Some selected samples of such comparisons are shown in Figure 11. For example, Figures $11(\mathrm{a})$ and $11(\mathrm{~b})$ show $k_{\mathrm{b}}$ versus $d / t_{\mathrm{fc}}$ and $m_{\mathrm{b}}$ versus 


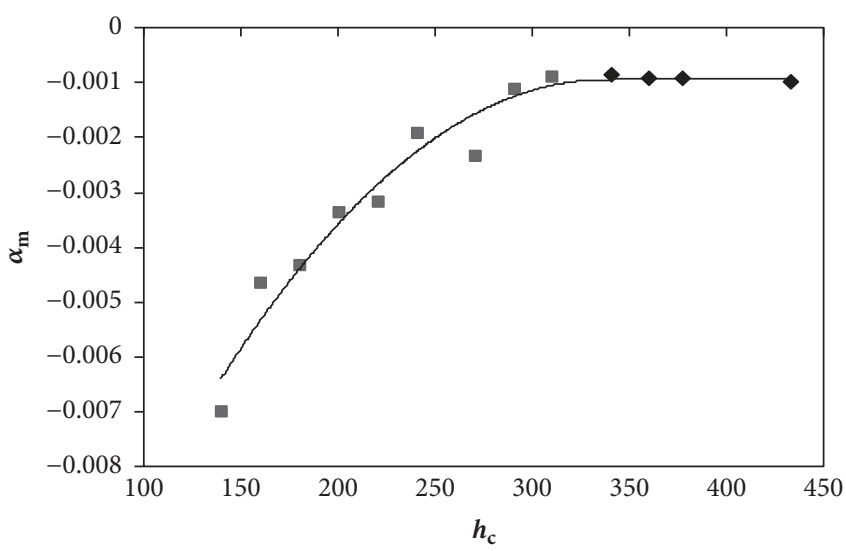

- HEM 300 - HEM 400

- HEM 120 - HEM 280

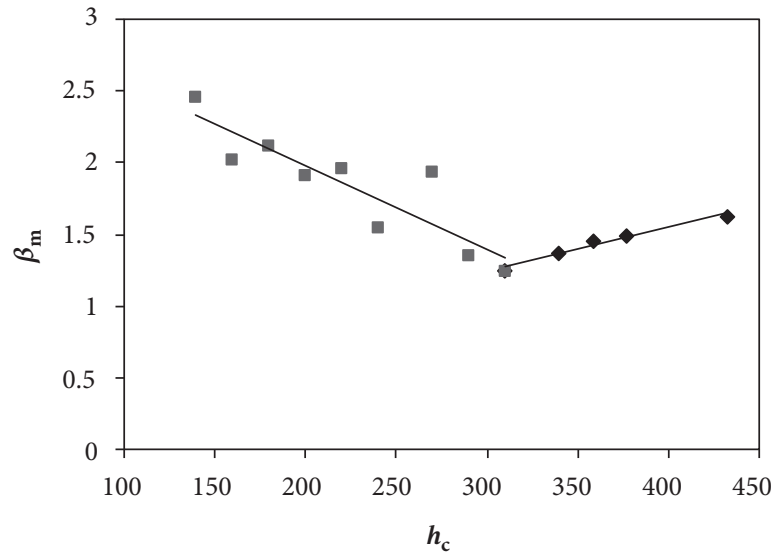

- HEM 300 - HEM 400

- HEM 120 - HEM 280

FIGURE 10: $\alpha_{\mathrm{m}}$ (a) and the intercept $\beta_{\mathrm{m}}$ (b) of equation (5) and equation (6).
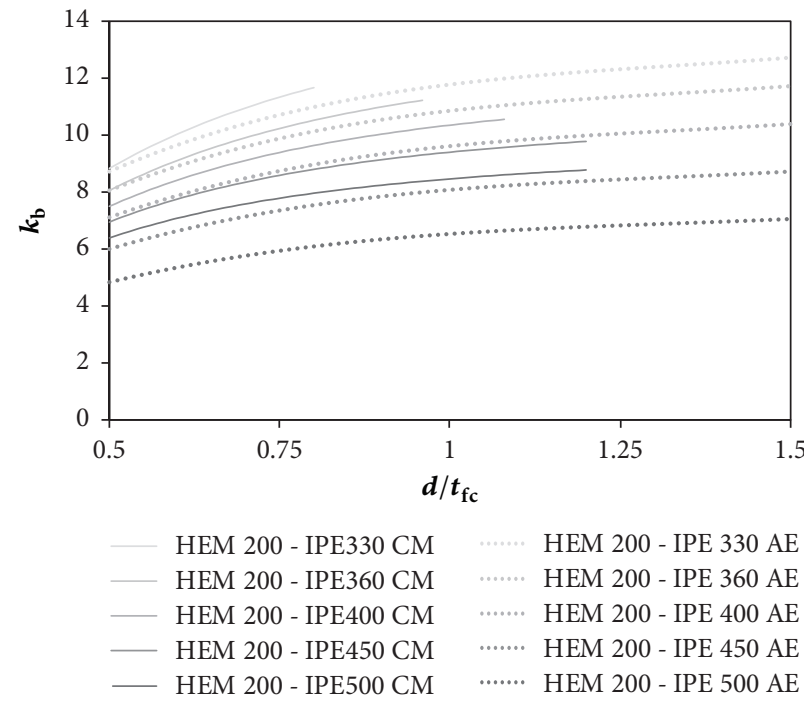

(a)
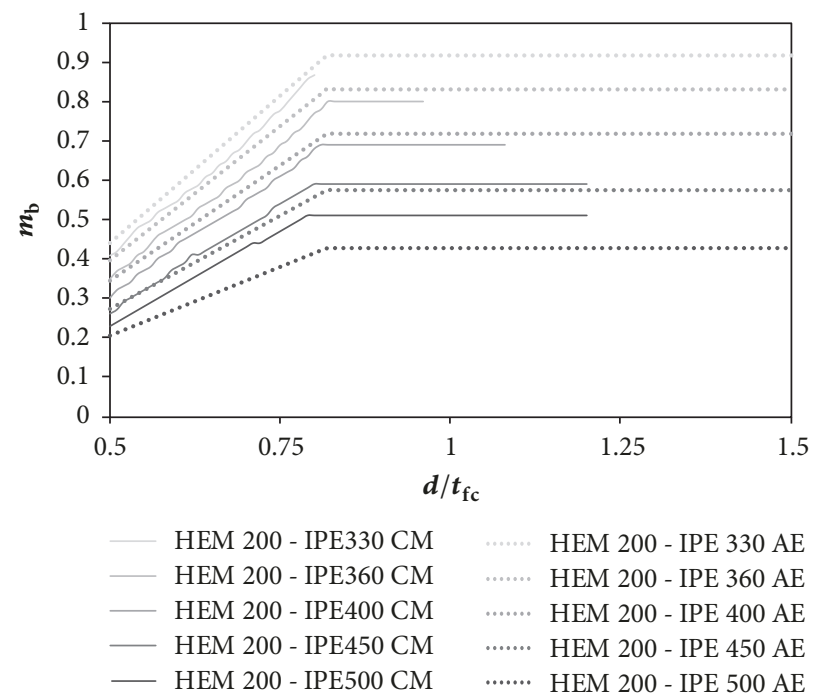

(b)

FIGURE 11: $k_{\mathrm{b}}$ versus $d / t_{\mathrm{fc}}(\mathrm{a})$ and $m_{\mathrm{b}}$ versus $d / t_{\mathrm{fc}}$ (b) relationships obtained using both the EC3 component method (CM) and the approximate equations (AE) for beam-to-column joints having a HEM 200 column cross section [7].

$d / t_{\mathrm{fc}}$ relationships obtained for the beam-to-column joints having a HEM 200 column cross section.

In the following, results corresponding to specific values of the ratio $d / t_{\mathrm{fc}}$ are discussed. They were selected among others due to being associated with the highest values of the difference between the two methods. The bar charts in Figures 12(a) and 12(b) compare normalized stiffness of beam-to-column joints resulting from the application of the component method (dark grey series) and the proposed approximate equations (light grey series). Such calculations consider $d / t_{\mathrm{fc}}$ equal to 0.5 (Figure $12(\mathrm{a})$ ) and 1.5 (Figure 12(b)). As illustrated, the approximate equations generally provide smaller value of $k_{\mathrm{b}}$ than the EC3 method. Overestimations are observed in few cases, associated with both larger and smaller column section depths.

Quantitatively, the difference between the two methods described as the percentage of difference is given in Figures 13(a) and 13(b). As displayed, the percentage of difference varies from $0 \%$ to $24 \%$ for $d / t_{\mathrm{fc}}=0.5$ and from $0 \%$ to $24 \%$ for $d / t_{\mathrm{fc}}=1.5$. On average the difference is about $10 \%$ for the normalized stiffness.

As far as the normalized resistance, in Figures 14(a) and 14(b), results of the component method application are compared with those related to the approximate equations, 


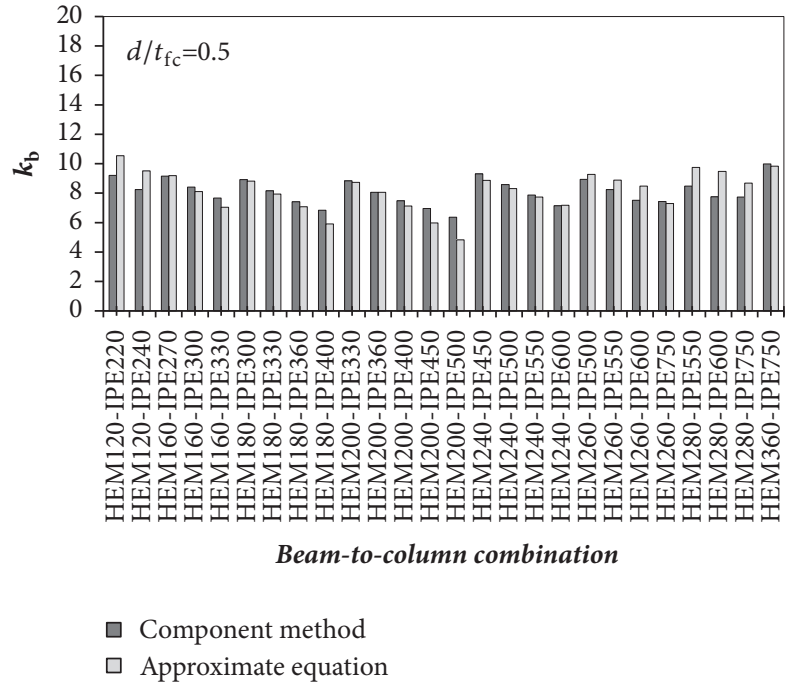

(a)

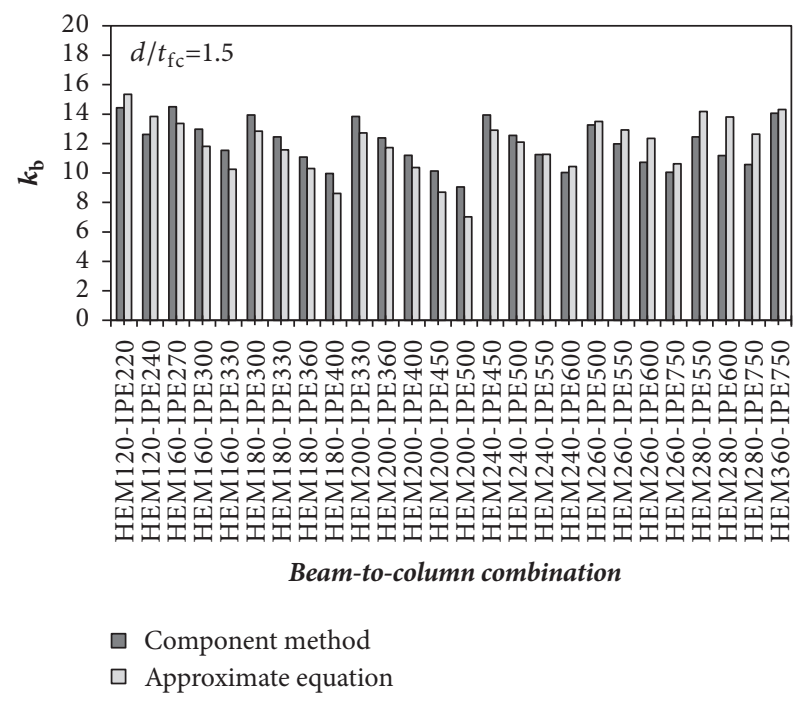

(b)

FIGURE 12: Accuracy of the approximate equations for selected values of the ratio $d / t_{\mathrm{fc}}$ : normalized stiffness.

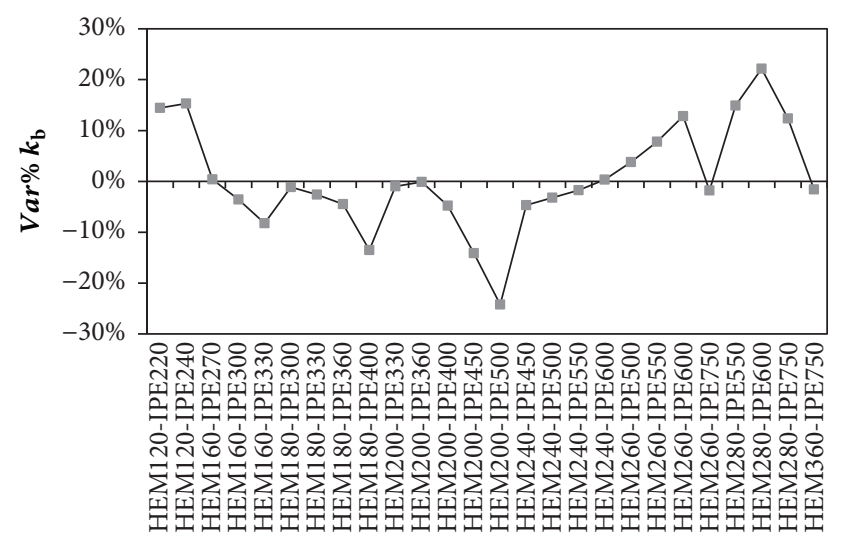

Beam-to-column combination

$$
\rightarrow d / t_{\mathrm{fc}}=0.5
$$

(a)

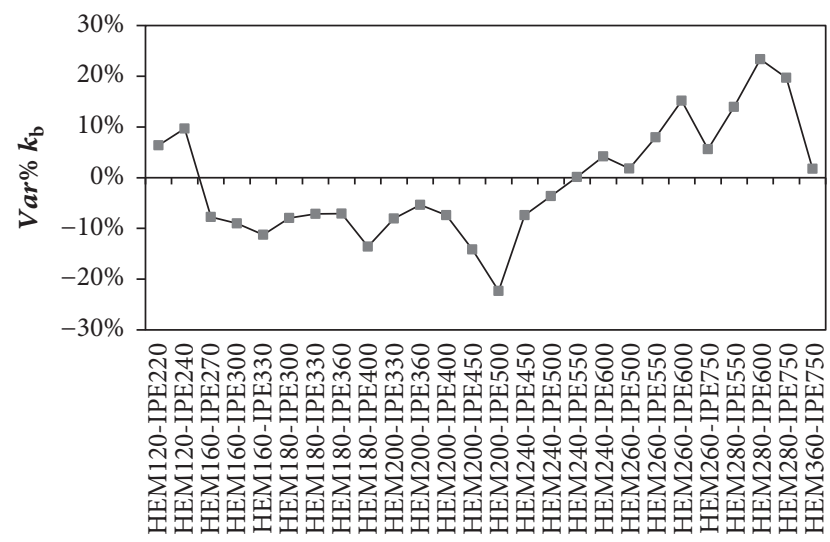

Beam-to-column combination

$$
\rightarrow-d / t_{\mathrm{fc}}=1.5
$$

(b)

FIGURE 13: Accuracy of the approximate equations in terms of percentage of difference for selected values of the ratio $d / t_{\mathrm{fc}}$ : normalized stiffness [7].

for $d / t_{\mathrm{fc}}$ equal to 0.5 and 0.8 , respectively. As shown, in most cases approximate equations appear to overestimate the normalized resistance for $d / t_{\mathrm{fc}}=0.5$, while the opposite is observed for $d / t_{\mathrm{fc}}=0.8$. Quantitative details of such comparison are provided in Figures 15(a) and 15(b). The percentage of difference between the two procedure varies from $0 \%$ to $17 \%$ for $d / t_{\mathrm{fc}}=0.5$ and from $0 \%$ to $18 \%$ for $d / t_{\mathrm{fc}}=0.8$. On average the difference is about $7 \%$.

In conclusion, it can be said that the differences between the approximate equations and the component method are within the range of variations found in the theoretical versus experimental results comparison. Therefore, the proposed approximate equations are considered acceptable.

\section{Conclusions}

A statistical assessment of the EC3 component method indicates that the mechanical approach provides a sufficiently reliable estimation of joint plastic resistance. Instead, the initial stiffness tends to be overestimated. The average ratio of theoretical and experimental values of moment resistances was 0.87 , for extended end-plate joints, and 1.07, for flush end-plate joints. The ratio between the theoretical and the experimental initial stiffness has a mean value equal to 1.50 for extended end-plate joints and 2.62 for flush end-plate joints. A parametric application of the component method led to the development of simplified design/analysis tools. Examples of 


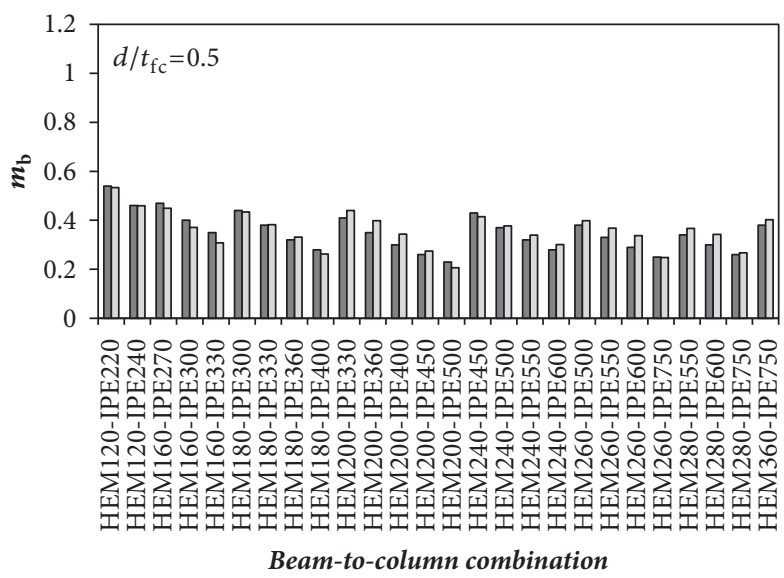

$\square$ Component method

$\square$ Approximate equation

(a)

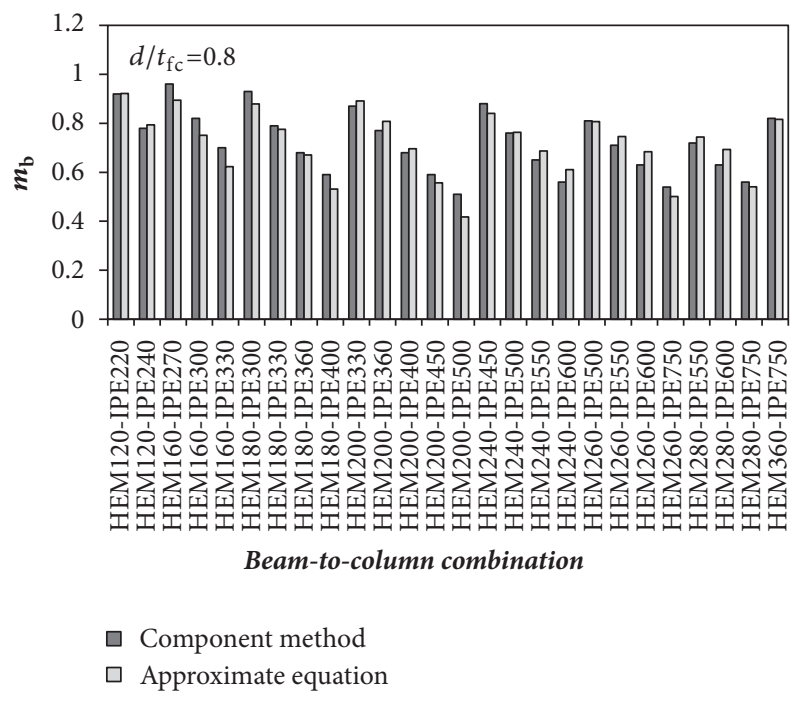

(b)

FIGURE 14: Accuracy of the approximate equations for selected values of the ratio $d / t_{\mathrm{fc}}$ : normalized resistance.

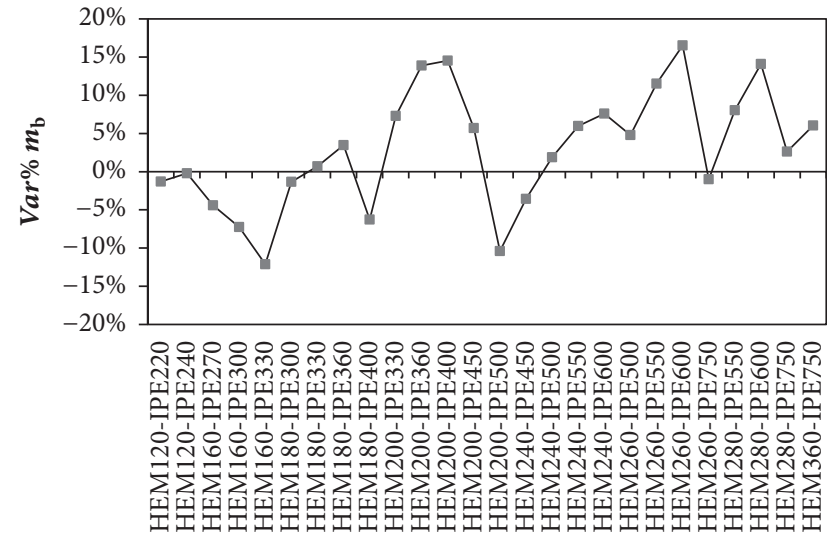

Beam-to-column combination

$\rightarrow-d / t_{\mathrm{fc}}=0.5$

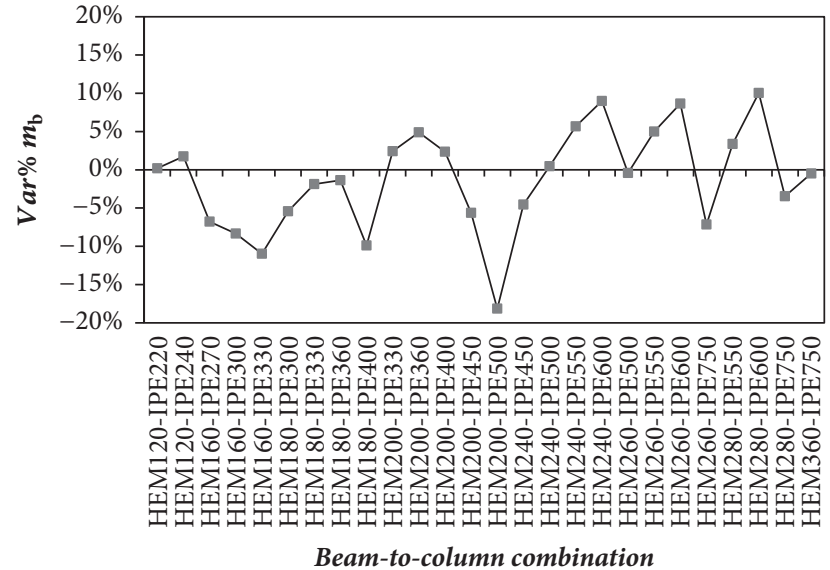

$-d / t_{\mathrm{fc}}=0.8$

(a)

(b)

FIGURE 15: Accuracy of the approximate equations in terms of percentage of difference for selected values of the ratio $d / t_{\mathrm{fc}}$ : normalized resistance [7].

such tools were provided in the form of design charts, which allows for a quick evaluation of the joint structural properties. The design charts could be used in the initial phases of the design process, in order to identify joint configurations and geometrical properties satisfying specified structural performances. Approximate generalized equations were also proposed to quickly estimate normalized stiffness and resistance of extended end-plate joints. The latter are preliminary results subject to further elaborations. The accuracy of the analytical equations was evaluated by comparing the relevant predictions with the numerical results from the component method. The simplified equations result in a normalized moment resistance $7 \%$ smaller than the theoretical value obtained by the component method, on average. The average difference is about $10 \%$ in case of normalized stiffness. Such differences are well within the range of differences found from the theoretical versus experimental results comparisons.

\section{Conflicts of Interest}

The authors declare that they have no conflicts of interest.

\section{Acknowledgments}

The authors gratefully acknowledge financial support from the European Union's Research Fund for Coal and Steel (RFCS) Research Programme under Grant Agreement no. RFSR-CT-2010-00029. 


\section{References}

[1] G. Della Corte, G. De Matteis, R. Landolfo, and F. M. Mazzolani, "Seismic analysis of MR steel frames based on refined hysteretic models of connections," Journal of Constructional Steel Research, vol. 58, no. 10, pp. 1331-1345, 2002.

[2] C. Faella, V. Piluso, and G. Rizzano, Structural Steel Semirigid Connections, CRC Press, Florida, FL, USA, 2000.

[3] J. P. Jaspart, “General report: session on connections," Journal of Constructional Steel Research, vol. 55, no. 1-3, pp. 69-89, 2000.

[4] M. E. Lemonis and C. J. Gantes, "Mechanical modeling of the nonlinear response of beam-to-column joints," Journal of Constructional Steel Research, vol. 65, no. 4, pp. 879-890, 2009.

[5] European Committee for Standardisation (CEN), "Eurocode 3, Design of steel structures, part 1-8: design of joints (EN 1993-18:2005), Brussels," 2005.

[6] R. Landolfo, "European qualification of seismic resistant steel bolted beam-to-column joints: the Equaljoints project," in Proceeding of the 8th International Workshop on Connections in Steel Structures, Boston, MA, USA, May 2016.

[7] G. Terracciano, G. D. Corte, G. Di Lorenzo, and R. Landolfo, "I nodi flangiati trave-colonna nelle strutture di acciaio - Metodi e strumenti per il progetto e la verifica (in Italian)," Precast Design, no. 10, http://www.prefabbricazioneweb.it/Articolo/ 1767/I_nodi_flangiati_trave_colonna_nelle_strutture_di_acciaio .html, 2014.

[8] E. A. Sumner and T. M. Murray, "Behavior of extended endplate moment connections subject to cyclic loading," Journal of Structural Engineering, vol. 128, no. 4, pp. 501-508, 2002.

[9] A. M. Girão Coelho, F. S. K. Bijlaard, and L. Simões da Silva, "Experimental assessment of the ductility of extended end plate connections," Engineering Structures, vol. 26, no. 9, pp. 11851206, 2004.

[10] P. Nogueiro, L. Simões Da Silva, R. Bento, and R. Simões, "Experimental behaviour of standardised european end-plate beam-to-column steel joints under arbitrary cyclic loading," in Proceedings of the International Colloquium on Stability and Ductility of Steel Structures (SDSS '06), pp. 951-960, Lisbon, Portugal, September 2006.

[11] A. M. Girão Coelho and F. S. K. Bijlaard, "Experimental behaviour of high strength steel end-plate connections," Journal of Constructional Steel Research, vol. 63, no. 9, pp. 1228-1240, 2007.

[12] Y. Shi, G. Shi, and Y. Wang, "Experimental and theoretical analysis of the moment-rotation behaviour of stiffened extended end-plate connections," Journal of Constructional Steel Research, vol. 63, no. 9, pp. 1279-1293, 2007.

[13] G. Shi, Y. Shi, and Y. Wang, "Behaviour of end-plate moment connections under earthquake loading," Engineering Structures, vol. 29, no. 5, pp. 703-716, 2007.

[14] M. Tahir and A. Hussein, "Experimental tests on extended endplate connections with variable parameters," Steel Structures, vol. 8, pp. 369-381, 2008.

[15] F. Iannone, M. Latour, V. Piluso, and G. Rizzano, "Experimental analysis of bolted steel beam-to-column connections: component identification," Journal of Earthquake Engineering, vol. 15, no. 2, pp. 214-244, 2011.

[16] A. Abidelah, A. Bouchaïr, and D. E. Kerdal, "Experimental and analytical behavior of bolted end-plate connections with or without stiffeners," Journal of Constructional Steel Research, vol. 76, pp. 13-27, 2012.
[17] B. M. Broderick and A. W. Thomson, "The response of flush end-plate joints under earthquake loading," Journal of Constructional Steel Research, vol. 58, no. 9, pp. 1161-1175, 2002.

[18] L. Simões Da Silva, L. R. O. De Lima, P. C. G. Da S. Vellasco, and S. A. L. De Andrade, "Behaviour of flush end-plate beamto-column joints under bending and axial force," Steel and Composite Structures, vol. 4, no. 2, pp. 77-94, 2004.

[19] B. M. Broderick and A. W. Thomson, "Moment rotation response of flush end-plate joints under cycling loading," Steel Structures, vol. 5, pp. 441-451, 2005.

[20] G. Terracciano, Yield and ultimate rotations of beam-to-column end-plate connections [Ph.D. Thesis], Department of Structures for Engineering and Architecture, University of Naples Federico II, 2013. 


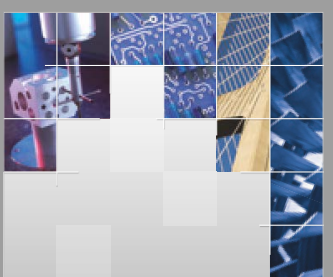

\section{Enfincering}
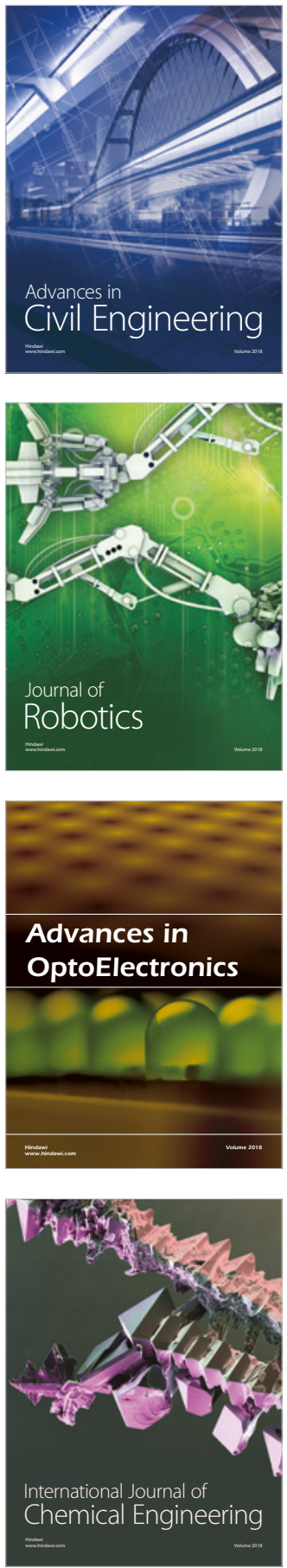

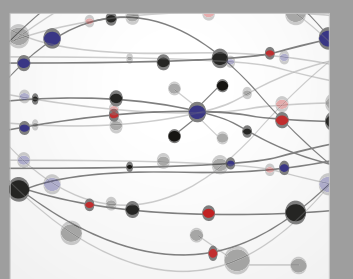

\section{Rotating \\ Machinery}

The Scientific World Journal

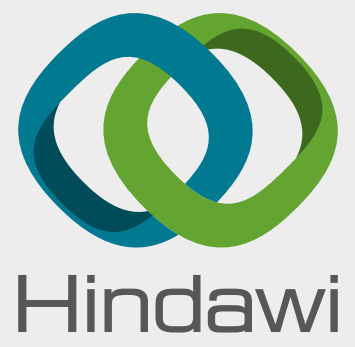

Submit your manuscripts at

www.hindawi.com
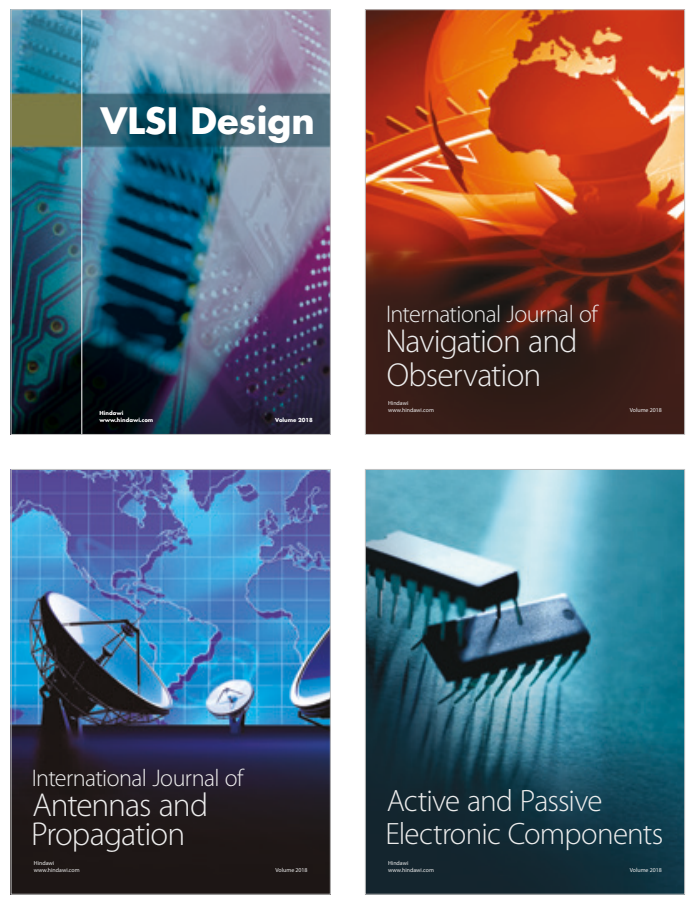
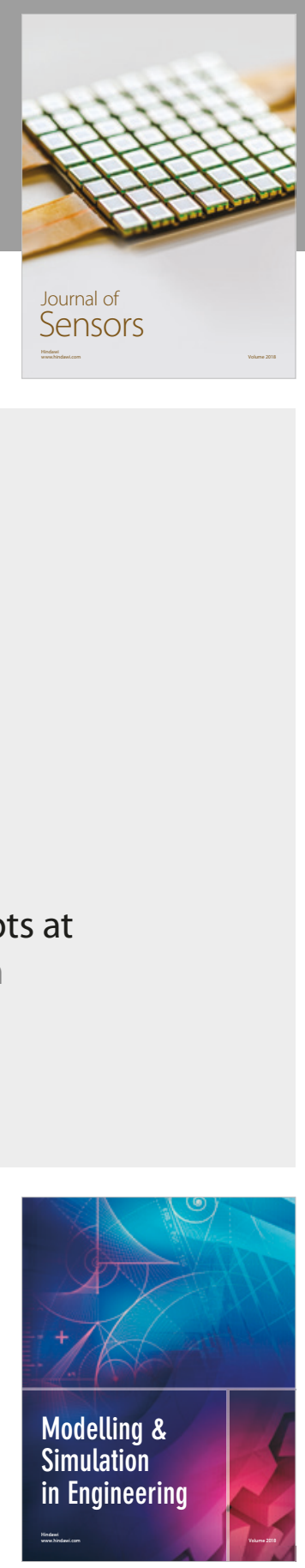

\section{Advances \\ Multimedia}
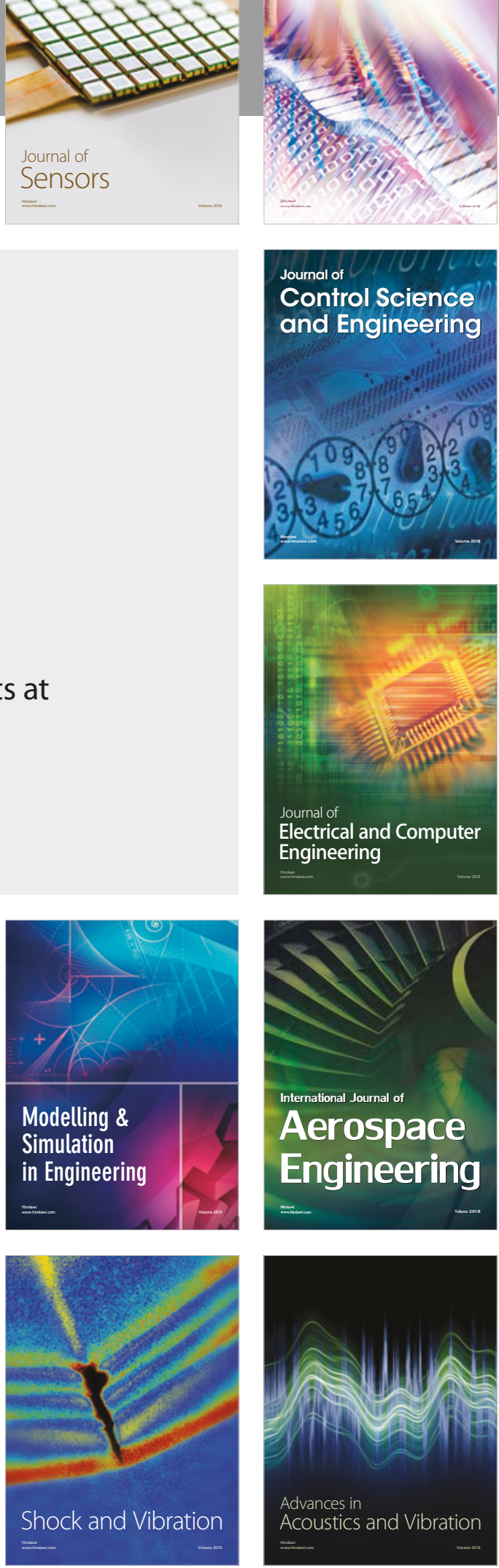